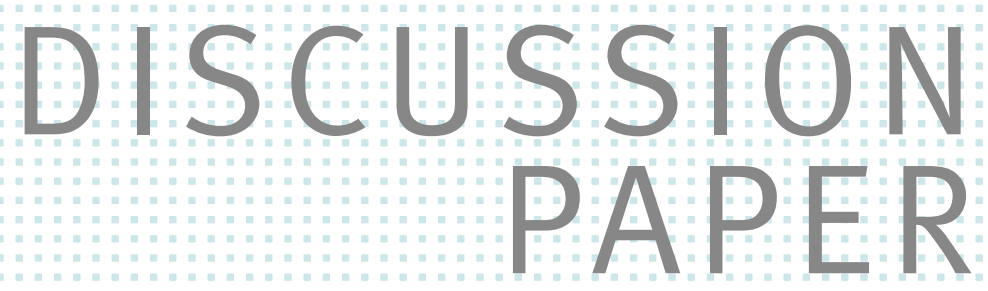

// FLORIAN BAUMANN, TIM FRIEHE, AND TOBIAS WENZEL

\title{
Imperfect Information About Consumer Rights: Implications for Efficiency and Distribution
}




\title{
Imperfect Information About Consumer Rights: Implications for Efficiency and Distribution
}

\author{
Florian Baumann* $\quad$ Tim Friehe $^{\dagger} \quad$ Tobias Wenzel ${ }^{\ddagger \S}$
}

December 10, 2021

\begin{abstract}
This paper shows that the provision of consumer rights can decrease welfare when some consumers remain ignorant of these rights. We find that consumers uninformed about a mandated warranty demand excessively safe products in some circumstances. In other circumstances, uninformed consumers buy the efficient product variety like informed consumers but the former cross-subsidize the latter via firms' pricing. With respect to the salient policy option of improving information about consumer rights, we find that increasing the share of informed consumers may actually raise the risk of inefficiency.
\end{abstract}

Keywords: consumer policy; imperfect information; efficiency; product safety; distribution.

JEL Codes: D18, K12, K13.

*ZEW Mannheim, L 7,1, 68161 Mannheim, Germany. E-mail: florian.baumann@zew.de.

${ }^{\dagger}$ Public Economics Group (University of Marburg); Am Plan 2, 35037 Marburg, Germany. Email: tim.friehe@uni-marburg.de.

‡ZEW Mannheim, L 7,1, 68161 Mannheim, Germany \& University of Sheffield, Department of Economics, 9 Mappin St, S1 4DT Sheffield, UK. E-mail: tobias.wenzel@zew.de.

${ }^{\S}$ We would like to thank the participants of the 2021 Annual Conference of the German Law and Economics Association (Berlin, online), the 2021 Annual Conference of the European Association of Law and Economics (Barcelona, online), the 2021 Annual Conference of the European Association for Research in Industrial Economics (Bergen, online), the 2021 International Meeting in Law and Economics (Paris, online), and seminars at the ZEW for helpful comments and suggestions. 


\section{Introduction}

\subsection{Motivation and Main Results}

Knowing when and how to intervene in markets to improve their outcomes is critical for welfare and represents a long-standing challenge for policy makers. Several factors can motivate specific economic policies to protect consumers when they transact with potentially more powerful or knowledgeable firms. For example, potentially misleading or even fraudulent firm behavior and asymmetric information with respect to product quality or safety are concerns that strongly suggest government intervention to protect consumers' economic interests. In a classical contribution, Spence (1977) asserts that, when consumers underestimate the probability of product defects, they should be able to demand a remedy from firms in case of product failure. However, evidence exists that consumers' knowledge about their rights is imperfect (e.g., Bar-Gill and Davis, 2017; Blinder and Krueger, 2004; Wobker et al., 2014). For instance, in a representative 2010 study for the European Union, only 60 percent of consumers were aware of their right to return a good without giving a reason if they purchased the product using post, phone or internet, and only 40 percent of consumers knew that they are entitled to free repair or replacement should a new fridge break down after 18 months (European Commission (2011)). ${ }^{1}$ Although the empirical relevance of consumers' imperfect information about their rights is undisputed, whether this questions the desirability of providing consumer rights in the first place has not been considered in the previous literature.

This paper shows that the provision of consumer rights can decrease welfare when some consumers remain ignorant of them. In our framework, product failure may result when the firm invests in normal care but will never obtain should the firm choose high care. A product failure can be repaired at a cost. By assumption, it is efficient that the firm sticks to normal care and that the product is repaired in the event of product failure. The policy maker may or may not mandate

\footnotetext{
${ }^{1}$ Such misperceptions of rights are also important in other life domains. For example, Kim (1997) shows that many employees in the United States who may be dismissed "at will" actually believe that they are protected against dismissal without just cause.
} 
a warranty that effectively concerns who is legally responsible for repair costs. If a warranty is mandated, firms are obliged to repair any product failure at zero cost for the consumer. In an effort to represent the empirically widely documented consumer misperceptions, we assume that only a share of consumers understand their rights in the event of a product failure, whereas the remaining consumers believe that they will always have to pay for any eventual repair (as they would be ignorant of any mandatory warranty). ${ }^{2}$

In our basic model we assume competitive firms and risk-neutral consumers. In case no warranty is mandated, all consumers buy the efficient normal-care product and incur the expected repair costs themselves. However, with a warranty mandate, circumstances exist in which a segmented market outcome can arise: uninformed consumers buy the excessively safe product while informed consumers purchase the product with efficient care. This can result because uninformed consumers overestimate the full price of the product manufactured with efficient care (with full price in the meaning of Shavell (1987), for example). This results as consumers add the expected repair costs to the price charged by the firm where the latter already comprises the firm's expected repair costs, implying double counting of expected repair costs. In other circumstances, both uninformed consumers and informed ones demand the efficient normal-care product (as in the scenario without a mandatory warranty). This scenario in which the inefficiency from excessive care is avoided is more likely if the share of informed consumers is low and/or care is relatively costly while the expected repair cost is small. Importantly, even under these circumstances, the provision of consumer rights is still consequential when some consumers remain ignorant of them. This results from the fact that the mandated warranty redistributes from uninformed consumers

\footnotetext{
${ }^{2}$ Our model is also representative of other circumstances. For example, one product may require a future update to maintain the consumer's valuation, while another product may have inefficiently comprehensive capabilities at the outset which, however, obviate any future update. If consumers do not know who bears the expected update costs, they may prefer the very comprehensive capability product variety. We may also consider the case in which consumers can buy a product online and in which the consumer policy concerns who is financially responsible for return shipping costs if the consumer is unsatisfied with the delivered item. The consumer may inefficiently try to exclude any return shipping cost risk by making the additional investment of a costly product inspection in a brick-and-mortar store before the online purchase. Moreover, it is important to note that heterogeneity with respect to the willingness to claim consumer rights, due to limited financial resources or knowledge about legal procedure and/or legal council, has effects similar to heterogeneity with respect to knowledge of consumer rights. For example, Engstrom (2011) reports that individuals from groups with low socio-economic status lack legal access. This analogy signifies an even wider applicability of our analysis.
} 
to informed ones because all consumers pay for the latter's expected repairs costs via the product's price while uninformed consumers in addition pay in full for their own repairs. This also explains why a high share of informed consumers or high expected repair cost make the scenario in which this cross-subsidization happens less likely. With the cross-subsidization getting more costly it becomes more likely that the inefficiently safe product variant is the more attractive bargain for uninformed consumers. This is a critical observation when it comes to providing consumer-rights information as a possible policy response to consumers' ignorance. Increasing the share of informed consumers may actually lead to a move from the cross-subsidization equilibrium to the equilibrium entailing the inefficient high-safety product.

In addition to our basic model, we analyze two variations: one in which we consider a monopolistic firm instead of competitive ones and another version in which consumers are risk averse instead of risk neutral. We find that the main result from our basic model - providing consumer rights can reduce welfare if some consumers remain ignorant of them - is robust to these modeling variations. As in the basic model, the fundamental reason is that firms may offer an excessively safe product although it is socially undesirable. In contrast to our analysis of the basic model, with monopolistic price setting, the fact that the firm offers the high-safety product to uninformed consumers can be welfare enhancing if a mandated warranty is in place. However, the monopolist chooses to offer the high-safety product variant more often than is welfare maximizing. With riskaverse consumers and competitive risk-neutral firms, a mandated warranty conveys the welfare gain of an efficient risk allocation between firms and informed consumers. However, the corresponding increase in welfare can be dominated by the welfare loss that results if firms offer the excessively safe product to uninformed consumers.

Our results highlight that the existence of imperfect information about principally desirable consumer rights can seriously question whether providing these rights is in the society's interest. An answer in the negative may result even if the share of uninformed consumers is small. Given that the imperfectness of consumers' information is widely accepted, our finding has wide-reaching policy implications. Furthermore, even absent a loss in efficiency, consumer ignorance can induce 
substantial distributional effects. Informed consumers may gain at the expense of ignorant consumers where the latter are more likely to belong to more vulnerable and disadvantaged groups. Also in this way, such a consumer protection policy may fail to achieve its main objectives.

\subsection{Related Literature}

Our paper analyzes whether some consumers' ignorance of their rights can question the social desirability of providing consumer rights in the first place. We contribute to the previous literature mainly in two ways.

First, we contribute to the law-and-economics strand of the literature in which it is commonly assumed that agents will (at least on average) become aware of and correctly understand regulations as they apply to them. Misperceptions are mostly analyzed to the extent to which they concern the choice regarding compliance with the law (e.g., Garoupa, 1999). Bar-Gill and Davis (2017) represent an important exception to the rule. They assume that all consumers misperceive the applicable legal standard and inquire about the optimality of adjusting the standard in response to the consumers' misperception. In contrast, in the present paper, we assume that some consumers perfectly understand the regulation while others do not and our results hinge on this asymmetry. In addition, in the setup of Bar-Gill and Davis, the application of a strictliability regime would resolve any problems stemming from consumers' misperceptions of their rights, whereas it is exactly such a policy that can create inefficiency in our setup.

Second, we contribute to the very rich literature on behavioral industrial organization. A growing number of papers consider the possibility that consumers may misperceive specific features of individual products (e.g., Gabaix and Laibson, 2006; Armstrong and Vickers, 2012). ${ }^{3}$ In our paper, consumers may remain ignorant about their legal rights as they pertain to all transactions on the market. Nevertheless, our result regarding the redistribution from uninformed to informed consumers when all consumers buy the normal-care product is reminiscent of important papers from this literature such as Gabaix and Laibson (2006) and Armstrong and Vickers (2012). In

\footnotetext{
${ }^{3}$ Recent surveys on this literature are Grubb (2015) and Heidhues and Kőszegi (2018).
} 
this sense, our paper also contributes to the question whether the presence of informed consumer offers protection to less informed consumers, as is discussed, for instance, in Armstrong (2015). Interestingly and in contrast to existing papers, in our setting, redistribution from uninformed consumers to informed ones can be created by extending consumer rights.

\subsection{Plan of the Paper}

In Section 2, we present the basic model with competitive firms and risk-neutral consumers and compare the no-warranty regime to that in which a warranty is mandated. The case of a monopolistic firm is considered in Section 3, whereas Section 4 contains the analysis featuring risk-averse consumers. Section 5 concludes. Proofs, if not obvious from the arguments in the main text, are relegated to our appendix.

\section{The Basic Model and Analysis}

\subsection{The Basic Model}

In our basic model, risk-neutral consumers have a valuation of $v$ per unit of the product supplied by a competitive industry at a constant per-unit cost $c$, where $v>c \geq 0$. Consumers decide whether or not to buy one unit of the product. The firm can apply normal or high care in the manufacturing process. If the product is manufactured with normal care, the product experiences a failure with probability $\pi$. The realization of a product failure is independent across consumers. A failure implies the loss of the consumer's product valuation $v$ but can be perfectly remedied at a fixed repair cost $r$. Repair is efficient, i.e., $r<v$. If the product is manufactured with high care instead, the firm incurs an additional per-unit safety cost $x$ which excludes the possibility of a product defect. ${ }^{4}$ Each firm's choice between normal and high care is common knowledge. ${ }^{5}$

\footnotetext{
${ }^{4}$ The assumption that high safety ensures no product failure is used for convenience but not critical to our main results.

${ }^{5}$ It is common to assume that product safety is observable to consumers (see, e.g., Daughety and Reinganum, 2006). For papers considering repercussions of asymmetric information about product safety, refer to Daughety and Reinganum (1995), for example.
} 
We assume that $v>c+x$ and $x>\pi r=\rho$, where $\rho$ is the expected repair costs. Thus, consumption benefits surpass expected per-unit costs for both product types. The latter assumption signifies that the additional cost for high care exceeds the associated benefit in terms of lower expected product repair costs. Consequently, in the efficient allocation, consumers buy one unit of the normal-care product which is repaired in the event of a product failure.

The firm-consumer interaction is guided by consumer law. We distinguish two legal regimes and assume that firms are always bound by the applicable legal rules (as in, e.g., Daughety and Reinganum, 2006). In the first regime, consumers bear the risk of a product failure, that is, they pay for repair in the event of product failure. In the second regime, a mandatory warranty requires firms to repair defective products at own costs. Our analysis is motivated by the empirical observation that some consumers are unaware of their rights. This is reflected in our setup by assuming that some consumers, share $1-\alpha$, are ignorant of their right to demand repair at no costs when the warranty is mandatory. Consequently, with a mandated warranty, informed consumers understand that the purchase of a normal-care product implies a full price that consists only of the price paid to the firm; uninformed consumers instead consider a full price that includes both the price paid to the firm and the expected repair costs.

To derive the market equilibrium, we consider the following timing. In stage 1, firms simultaneously choose prices and whether to offer a product with normal or high care. In stage 2 , consumers make their purchase decisions.

\subsection{The Analysis}

In this section, we compare the competitive market outcome when there is no mandated warranty to the one when a mandatory warranty is in place.

\subsubsection{No Mandated Warranty (Laissez-Faire)}

In the laissez-faire regime, consumers bear expected repair costs $\rho$ when they buy a product manufactured with normal care. The consumer's full price $q_{n}$ includes the transfer to the firm $p_{n}$ 
and the expected repair costs $\rho, q_{n}=p_{n}+\rho .^{6}$ A firm's use of high care excludes the possibility of a product failure such that $q_{h}=p_{h}$. However, the firm incurs an additional care cost $x$.

The assumption of a competitive industry implies prices equal to unit costs for every product offered. This leads to $p_{n}=c$ and $p_{h}=c+x$. Because the additional care costs $x$ outweigh the saving of expected repair costs $\rho$ by assumption, we have $q_{n}<q_{h}$. Thus, all firms offer the normal-care product in equilibrium which is purchased by all consumers. Firms earn zero profits.

\subsubsection{Mandated Warranty}

With a mandated warranty, consumers can demand that the firm repairs the product at no additional personal cost. We assume that some consumers are ignorant of their rights resulting from the warranty and that uninformed consumers do not use signals such as product prices to possibly infer the availability of a warranty. ${ }^{7}$ Firms cannot distinguish informed and uninformed consumers. Informed consumers (superscript $i$ ) understand that full prices coincide with market prices, $q_{n}^{i}=p_{n}$ and $q_{h}^{i}=p_{h}$, because firms have to repair defective products at no additional personal cost. In contrast, uninformed consumers (superscript ni) perceive full consumer prices $q_{n}^{n i}=p_{n}+\rho$ and $q_{h}^{n i}=p_{h}$.

We start with the following observation:

Lemma 1 With a mandatory warranty, informed consumers buy normal-care products in equilibrium.

With a mandated warranty, the market equilibrium will thus feature either both high- and normal-care products or only normal-care products. We elaborate on these equilibrium candidates in turn.

Consider the equilibrium candidate in which both the high- and the normal-care products are offered. Since informed consumers buy the normal-care product (see Lemma 1), it must be uninformed consumers who purchase the high-care product giving rise to a segmented-market

\footnotetext{
${ }^{6}$ Subscripts denote whether the firm has applied normal care $(n)$ or high care $(h)$.

${ }^{7}$ This assumption is usually imposed in industrial organization models assuming behavioral consumers (e.g., Heidhues and Köszegi, 2018).
} 
outcome. Competition ensures zero profits such that $p_{n}=c+\rho$ (i.e., the product's price matches the firm's expected per-unit repair costs) and $p_{h}=c+x$.

Next, consider the equilibrium candidate in which only the normal-care product is traded. Competition drives firms' expected profits to zero, implying $p_{n}=c+\alpha \rho$. This price reflects that only informed consumers (share $\alpha$ ) create expected repair costs for firms.

Proposition 1 shows that each candidate outomce can arise in equilibrium:

Proposition 1 (Mandated Warranty and Competitive Firms) Assume a mandated warranty and that competitive firms serve demand. (i) If $\alpha \geq \hat{\alpha}=(x-\rho) / \rho$, informed consumers buy the normal-care product at $p_{n}=c+\rho$ and uninformed consumers purchase the high-care product at $p_{h}=c+x$. (ii) If $\alpha<\hat{\alpha}$, all consumers buy normal-care products at $p_{n}=c+\alpha \rho$. Firms always earn zero profits.

With a mandated warranty, a unique market equilibrium exists. It features either both highand normal-care products or only normal-care products depending on how the share of informed consumers $\alpha$ compares to the relative increase in costs for a high-care product $(x-\rho) / \rho$. Firms have no incentive to offer the high-care product when the share of informed consumers is low or, equivalently, the additional care costs are relatively high. With only normal-care products on offer firms charge $p_{n}=c+\alpha \rho$. Uninformed consumers anticipate to pay $p_{n}+\rho$ and would thus be willing to pay at most $p_{n}+(1+\alpha) \rho$ for a high-safety product. This maximum price is not high enough to cover costs $c+x$ if the share of informed consumers is too low, $\alpha<\hat{\alpha}$. In contrast, with many informed consumers $(\alpha>\hat{\alpha})$, the equilibrium features both types of products. In this case, if a firm offering the normal-care product would like to attract uninformed consumers, it would have to lower its price below average per-unit costs $c+\alpha \rho$.

Proposition 1 clarifies that the socially desired outcome in which solely normal-care products are traded results only if the share of informed consumers is below a critical value. However, even without the inefficiency in terms of safety, the provision of consumer rights is not irrelevant but still critical due to its distributional consequences. When all consumers buy the normalcare product, firms' pricing cross-subsidizes informed consumers with transfers from uninformed 
consumers. The logic is similar to the one in Gabaix and Laibson (2006). Informed consumers obtain the product at a price below marginal costs (i.e., at $c+\alpha \rho$ instead of $c+\rho$ ) whereas uninformed consumers face a full price above marginal costs. Firms earn a profit equal to $\alpha \rho$ per unit sold to uninformed consumers and earn zero profits on average. The distributional effect also provides an intuition for why the equilibrium with only the normal-care product on offer is obtained only for low shares of informed consumers and not otherwise. As long as the share of informed consumers is not too high, the extent of cross-subsidization is limited, implying that the high-safety product is not attractive for uninformed consumers. This changes as the share of informed consumers and therefore the extent of cross-subsidization increases.

Proposition 2 summarizes the efficiency and distributional consequences of a mandated warranty:

Proposition 2 (Mandated Warranty's Effects with Competitive Firms) Assume that competitive firms serve demand. (i) If $\alpha \geq \hat{\alpha}$, a mandated warranty lowers efficiency relative to the laissez-faire regime. Informed consumers are unaffected by the mandated warranty, whereas uninformed consumers lose utility from it. (ii) If $\alpha<\hat{\alpha}$, a mandated warranty leaves efficiency unaffected relative to the laissez-faire regime. However, the mandated warranty induces a redistribution from uninformed consumers to informed consumers. Independent of the share of informed consumers, firms are indifferent between the mandated-warranty and the laissez-faire regime.

It is disconcerting that the provision of consumer rights by mandating a product warranty can lower efficiency when some consumers remain ignorant of their rights. In addition, even if there is no inefficiency, the purely distributional repercussions that result when the share of informed consumers is low will imply lower welfare for welfare functions that put a higher weight on disadvantaged individuals when some realistic correlation between socio-economic status and the status of being informed is assumed. Moreover, when some correlation between consumers' information about the warranty and their vulnerability as consumers is assumed, then the provision of consumer rights harms the people it is intended to protect most strongly. In case (i) of Proposition 2, uninformed consumer lose from the warranty because they ultimately purchase an inefficient 
product. In case (ii), uninformed consumers lose from the warranty because they cross-subsidize informed consumers.

Our results highlight that increasing consumers' awareness of their rights may be an important policy complement to the provision of consumer rights. At the same time, we find that the efficiency and distributional consequences of such an information policy are not straightforward:

Proposition 3 (Policy's Effects for Consumer Welfare with Competitive Firms) Assume a mandated warranty and that competitive firms serve demand. (i) If $\alpha \geq \hat{\alpha}$, increasing the share of informed consumers increases utility of the newly informed consumers and leaves others unaffected. Aggregate consumer welfare increases. (ii) If $\alpha<\hat{\alpha}$, increasing the share of informed consumers benefits newly informed consumers but harms all other consumers via a higher price. Aggregate consumer welfare remains unchanged. (iii) Increasing the share of informed consumers from just below to just above $\hat{\alpha}$ benefits newly informed consumers but harms all already informed consumers. Aggregate consumer welfare decreases.

We illustrate these results in Figures 1 and 2. As long as $\alpha<\hat{\alpha}$ firms offer only the normal-care product and an increase in the share of informed consumers means that firms more often pay for repairs. The additional costs are passed on to all consumers (see Figure 1). With newly informed consumers being better off, in this range, consumer welfare is constant at $v-c-\rho$ (see Figure 2).

At some point, the extent to which uninformed consumers cross-subsidize informed ones becomes so large that the former prefer switching to the high-care product. Moving from the equilibrium with only the normal-care product to separated markets, informed consumers' utility experiences a downward jump in utility as uninformed consumers' cross-subsidization ceases (see Figure 1). Total welfare experiences a downward jump due to the introduction of the inefficient high-safety product variant (see Figure 2). In this segmented-markets scenario, more informed consumers are socially beneficial as the newly informed consumers switch from the inefficient product variant to the efficient one.

In summary, the economic policy of increasing the share of informed consumers can be welfaredecreasing and may be associated with unintended distributional effects by increasing the extent 


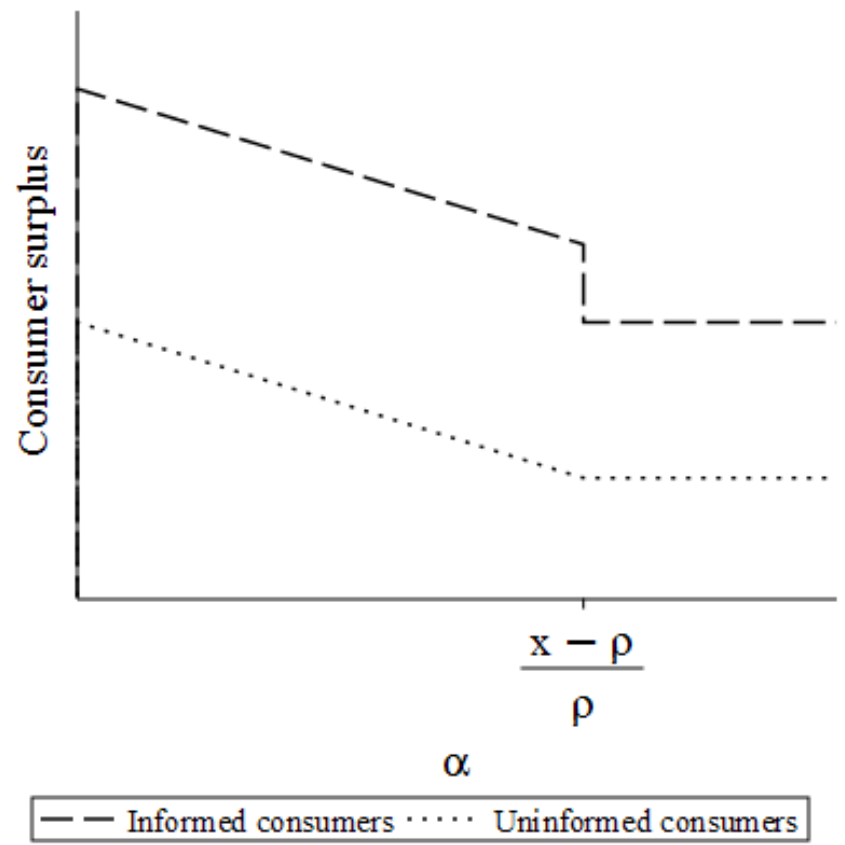

Figure 1: (Un)Informed Consumer's Utility and the Share of Informed Consumers

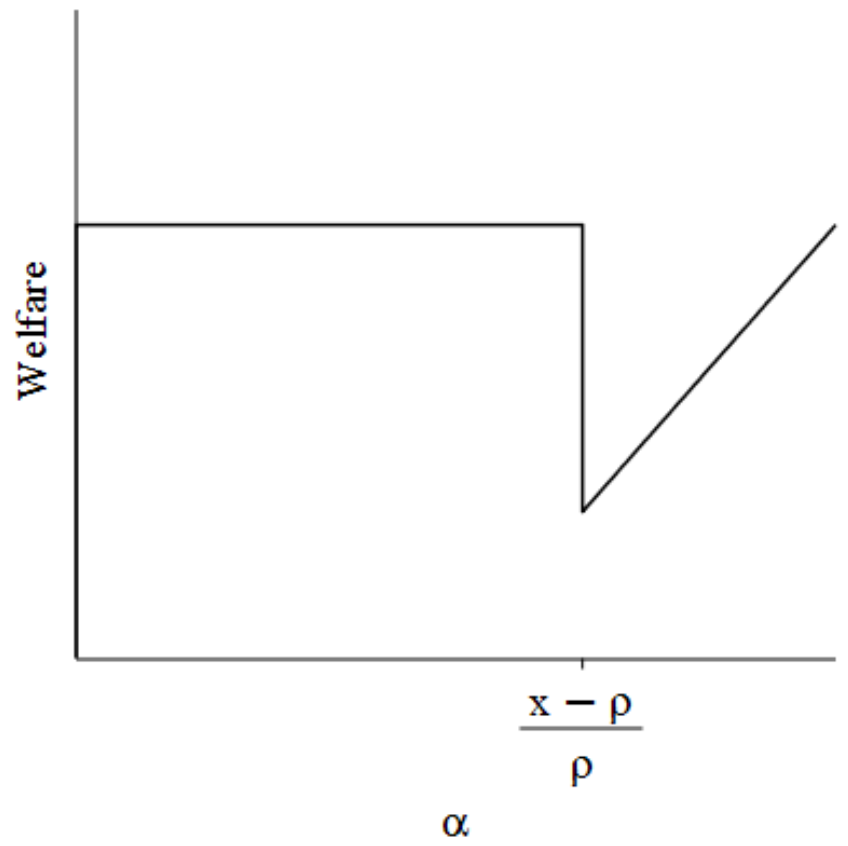

Figure 2: Total Welfare and the Share of Informed Consumers 
of cross-subsidization.

Besides the policy maker, firms could provide information about consumer rights. As the information pertains to consumer rights regarding all products, the information provision cannot generate a competitive advantage for a single firm. ${ }^{8}$ When the market equilibrium is such that both product variants are traded, firms earn zero profits with both consumer types and thus do not care about the share of informed consumers. When the market equilibrium is such that only normal-care products are offered, firms charge $c+\alpha \rho$, earning a profit only with uninformed consumers. In this case, turning a consumer with an unknown type into a consumer who is informed cannot raise profits but may actually result in a loss. Finally, also a shift in the share of informed consumers from below to above $\hat{\alpha}$ does not increase firms' profits which remain at zero, negating an incentive for firms to inform consumers. Therefore:

Remark: Firms have no incentive to inform uninformed consumers about their rights.

\section{The Case of a Monopolistic Firm}

In this section, we assume that a monopolistic firm serves demand and that consumers' valuations are uniformly distributed on the unit interval where $v^{\max }=1>1-c-x>0 .^{9}$ Without competitors that may lure consumers away from the firm, the monopolist can induce outcomes possibly out-of-equilibrium in the competitive framework.

\subsection{No Mandated Warranty (Laissez-Faire)}

In the laissez-faire regime, a consumer's willingness to pay for a normal-care product is $v-\rho$ and $v$ for a high-care product. Because additional care costs exceed the increase in the consumers' willingness to pay, the monopolist offers only the normal-care product. ${ }^{10}$ Consumers with valuations

\footnotetext{
${ }^{8}$ The logic of the finding that competitive firms may have no incentive to inform consumers is similar to the one in Gabaix and Laibson (2006).

${ }^{9}$ We generalize the framework by extending to heterogeneous valuations to obtain a demand function that varies continuously with the attractiveness of the offered product. However, our main insights obtain also if we maintain the assumption that consumers differ only in their level of information.

${ }^{10}$ For every $p_{h}$ charged when selling only the high-care products, the firm obtains the same level of demand when only selling the normal-care product by setting $p_{n}=p_{h}-\rho$. However, per-unit profits are higher with the
} 
$v \geq \hat{v}$ buy the product, where $\hat{v}=p_{n}+\rho$. The firm maximizes its profits,

$$
\Pi=\left(p_{n}-c\right)\left(1-p_{n}-\rho\right)
$$

using the profit-maximizing price

$$
p_{n}=\frac{1+c-\rho}{2}
$$

This outcome induces profits and welfare amounting to

$$
\Pi^{N}=\frac{(1-c-\rho)^{2}}{4} \quad W^{N}=\frac{3 \Pi^{N}}{2} .
$$

Only the efficient normal-care product is traded in equilibrium. Market power causes an inefficiently low equilibrium output level (as welfare would be maximal when the price amounts to marginal $\operatorname{costs} c)$.

\subsection{Mandated Warranty}

With a mandated warranty, the firm can choose whether to induce an outcome in which all consumers buy the normal-care product or an outcome in which (un)informed consumers buy the (high-)normal-care product. ${ }^{11}$ We first derive the profit-maximizing outcome in the two cases and then explain which one is selected by the firm.

Markets for Normal- and High-Care Products: The outcome in which (un)informed consumers buy the (high-)normal-care product can only result when the self-selection constraints

$$
p_{n} \leq p_{h} \leq p_{n}+\rho
$$

normal-care variant since $p_{n}-c=p_{h}-c-\rho>p_{h}-c-x$.

${ }^{11}$ Offering only the high-care product is a dominated strategy. The monopolist could always offer the normal-care product next to the high-care product and charge the same price for both products. Informed consumers would switch to the normal-care product which leads to a cost saving for the firm equal to $x-\rho$ per consumer switching to the normal-care product. 
are fulfilled. The first inequality ensures that informed consumers prefer the normal-care product, whereas uninformed consumers prefer the high-care product when the second inequality applies. Regarding participation in the market, informed consumers buy as long as $v \geq \hat{v}_{n}=p_{n}$, while uninformed consumers do so when $v \geq \hat{v}_{h}=p_{h}$. Expected repair costs are irrelevant for informed consumers as they demand repairs at no personal cost from the firm and for uninformed consumers as they demand high-care products.

The firm maximizes profits

$$
\Pi=\alpha\left(p_{n}-c-\rho\right)\left(1-p_{n}\right)+(1-\alpha)\left(p_{h}-c-x\right)\left(1-p_{h}\right)
$$

subject to the self-selection constraints, which results in ${ }^{12}$

$$
p_{n}=\frac{1+c+\rho}{2}+\max \left\{(1-\alpha) \frac{x-3 \rho}{2}, 0\right\} \quad p_{h}=\frac{1+c+x}{2}-\max \left\{\alpha \frac{x-3 \rho}{2}, 0\right\}
$$

The self-selection constraint for informed consumers, $p_{n} \leq p_{h}$, is non-binding for the firm's profit-maximization. In contrast, the constraint for uninformed consumers binds when additional care costs are high. Such high values of $x$ increase the firm's marginal costs and the optimal price in the market for the high-care product. For $x>3 \rho$, uninformed consumers would prefer the normal-care product if the firm would set prices according to unrestricted profit maximization. Accordingly, when $x>3 \rho$, the firm has to adjust prices for the normal-care (high-care) product upwards (downwards) to sustain the separated normal-care and high-care markets.

For $x \leq 3 \rho$, we obtain profits and welfare amounting to

$$
\Pi^{W, s e p}=\alpha \Pi^{N}+(1-\alpha) \frac{(1-c-x)^{2}}{4} \quad W^{W, s e p}=\frac{3 \Pi^{W, s e p}}{2} .
$$

Below we will argue that the firm never chooses separated markets when $x>3 \rho$ and therefore omit the respective welfare measures here.

\footnotetext{
${ }^{12}$ The derivation is relegated to our appendix.
} 
Market Only for Normal-Care Products: (Un)Informed consumers buy the normal-care product if $v \geq p_{n}\left(v \geq p_{n}+\rho\right)$. This signifies that some price levels will create positive demand only from informed consumers, namely when $1>p_{n} \geq 1-\rho$.

The firm chooses the price of the normal-care product to maximze

$$
\Pi=\alpha\left(p_{n}-c-\rho\right)\left(1-p_{n}\right)+(1-\alpha)\left(p_{n}-c\right) \max \left\{\left(1-p_{n}-\rho\right), 0\right\}
$$

where the firm incorporates expected repair costs only for informed consumers. The profitmaximizing price amounts to ${ }^{13}$

$$
p_{n}= \begin{cases}\frac{1+c+\rho}{2}-(1-\alpha) \rho & \text { for } \rho \leq \mathcal{R}=\frac{1-c}{1+2 \sqrt{\alpha}} \\ \frac{1+c+\rho}{2} & \text { for } \rho>\mathcal{R}\end{cases}
$$

The firm chooses to serve both consumer types if repair costs are not too high, $\rho<\mathcal{R}$. If the firm wants to attract both consumer groups, it asks for a price lower than the profit-maximizing price for informed consumers. The discount increases with the level of expected repair costs. As a result, the firm prefers serving only informed consumers when repair costs are high. The critical value $\mathcal{R}$ decreases in the share of informed consumers, that is, a higher value of $\alpha$ makes it more likely that only informed consumers will be served. For $\rho \leq \mathcal{R}$ we have

$$
\Pi^{W, \text { nosep }}=\Pi^{N}-\rho^{2} \alpha(1-\alpha) \quad W^{W, \text { nosep }}=W^{N}-\frac{\rho^{2} \alpha(1-\alpha)}{2} .
$$

Below, we will argue that the firm never chooses to trade only the normal-care product if $\rho>\mathcal{R}$.

We can now compare profit levels for the two cases. Proposition 4 summarizes the market equilibrium when a monopolistic firm serves the market subject to a mandated warranty:

Proposition 4 (Mandated Warranty and Monopolist) Assume a mandated warranty and

\footnotetext{
${ }^{13}$ The derivation is relegated to our appendix.
} 
that a monopolistic firm serves demand. Define

$$
\mathcal{T}=x^{2}-2 x(1-c)+2 \rho(1-c)+\rho^{2}(4 \alpha-1) .
$$

(i) If $\mathcal{T} \geq 0$, informed consumers purchase the normal-care product at $p_{n}=(1+c+\rho) / 2$ and uninformed consumers buy the high-care product at $p_{h}=(1+c+x) / 2$. (ii) If $\mathcal{T}<0$, all consumers buy normal-care products at $p_{n}=(1+c+\rho) / 2-(1-\alpha) \rho$.

Our main result from the basic model - a mandated warranty can induce trading of an inefficiently safe product - is robust to the consideration of market power. In addition, the way in which parameters make one or the other case more likely is also similar. Especially, the critical value $\mathcal{T}$ increases in the share of informed consumers such that the inefficient high-care product will be offered if the share of informed consumers surpasses a threshold. Higher additional care costs $x$ decrease while higher expected repair costs increases $\mathcal{T}$. In other words, it is less likely that the monopolist offers the high-care product for higher care costs and/or lower repair costs. ${ }^{14}$

In the present framework, the provision of consumer rights is welfare relevant even if only normal-care products are traded. This results from our consideration of heterogeneous valuations. The warranty affects price setting and introduces different perceived full prices for informed and uninformed consumers. With variable demand, this results in welfare-relevant alterations of purchase decisions.

Regarding consumers, similar distributional implications from the warranty arise with a monopolistic firm when compared to those in the setup with competitive firms. When the firm offers both products, informed consumers are indifferent with respect to the warranty (their full price is always $(1+c+\rho) / 2)$ whereas uninformed consumers lose from the introduction of the warranty (as their full price rises from $(1+c+\rho) / 2$ to $(1+c+x) / 2)$. When the firm offers only normalcare products, informed consumers gain from the warranty's introduction whereas uninformed consumers lose, as the full price for [un]informed consumers falls [increases] by $(1-\alpha) \rho[\alpha \rho]$. The monopolistic firm strictly prefers the laissez-faire to the mandated-warranty regime, whereas

\footnotetext{
${ }^{14}$ We have $\partial \mathcal{T} / \partial \alpha=4 \rho^{2}>0, \partial \mathcal{T} / \partial x=-2(1-c-x)<0$, and $\partial \mathcal{T} / \partial \rho=2(1-c-\rho)+8 \rho \alpha>0$.
} 
competitive firms were indifferent. With both products on offer, the monopolist shares some of the loss due to the introduction of the inefficient high-care product variant. In the equilibrium with only the normal-care product variant on offer, the distortion in prices between informed and uninformed consumers impedes monopolistic profit maximization.

In terms of total welfare, providing consumer rights is welfare-decreasing when some consumers remain ignorant of their rights. Informed consumers benefit when only normal-care products are traded. However, their gain is more than offset by the losses of uninformed consumers and the monopolist.

Interestingly, when we condition on having a mandated warranty and a monopolistic firm serving demand, trading of the high-care product can be socially optimal. This possibility did not exist in our basic model and results here from the fact that the high-care product opens up a second market, meaning it can raise output overall. However, the monopolists' and planner's incentives are not aligned. The firm introduces the high-care product variant even in circumstances in which it is not socially preferred. From a comparison of welfare levels, it follows that a segmented-market outcome (where informed and uninformed consumers purchase different products) should obtain only if

$$
x^{2}-2 x(1-c) x+2 \rho(1-c)-\rho^{2}(1-4 \alpha / 3)=\mathcal{T}-\rho^{2} 8 \alpha / 3>0 .
$$

We summarize the welfare and distributional results in Proposition 5:

Proposition 5 (Mandated Warranty's Effects with a Monopolist) Assume a mandated warranty and that a monopolistic firm serves demand. Both profits and welfare are always lower than in the laissez-faire regime. The firm offers the high-care product for more parameter combinations than is socially optimal. In addition, we find that (i) if $\mathcal{T} \geq 0$, informed consumers obtain the same level of utility as without a warranty while uninformed consumers are worse off, and, (ii) if $\mathcal{T}<0$, informed (uninformed) consumers are better (worse) off than in the laissez-faire regime.

We conclude our discussion of the monopoly case by considering the effects of informing consumers. Proposition 6 summarizes the main findings: 
Proposition 6 (Policy's Effects for Consumer Welfare with a Monopolist) Assume a mandated warranty and that a monopolistic firm serves demand. (i) If $\mathcal{T} \geq 0$, that is high- and normal-care products are traded, both profits and welfare increase in the share of informed consumers. (ii) If $\mathcal{T}<0$, the firm offers only the normal-care product and an increase in the share of informed consumers reduces (increases) profits and welfare for $\alpha<(>) 1 / 2$.

If the share of informed consumers is high enough to effect $\mathcal{T} \geq 0$, the firm offers both care levels. Any further increase of $\alpha$ increases welfare and profits by shifting consumers to the efficient normal-care product. If $\mathcal{T}<0$ applies, the firm offers only the normal-care product. Then, more informed consumers lower profits and welfare when the change leads to a more heterogeneous consumer population, that is, when the initial share of informed consumers is less than one half. Note that, due to our finding of the firm choosing market separation too often, a downward jump in welfare occurs when the share of consumers just surpasses the threshold to induce market segmentation.

These findings indicate another difference to the base model summarized in the final remark:

Remark: The monopolist can have an incentive to inform consumers about their rights, especially if the initial share of informed consumers is not too low.

\section{The Case of Risk-Averse Consumers}

In this section, we consider risk-averse consumers and risk-neutral firms. This setup entails additional welfare effects for a mandated-warranty regime. In contrast to our basic model, the social evaluation of the high-care product depends on the risk allocation. If firms carry the risk of product failure, risk concerns are no longer relevant and only the normal-care product should be offered. However, if risk lies with consumers, the high-care product may be second-best efficient. The first-best allocation requires risk-neutral firms to bear risk as the cheapest insurer.

Slightly adjusting the framework used in Polinsky (1983), we assume consumers with utility

$$
u(y)=y-s(y-E(y))^{2}
$$


where $y$ is the payoff in some state, $s \geq 0$ measures risk aversion and $E($.$) is the expectation$ operator. The case $s=0$ corresponds to our basic model, and larger values of $s$ imply greater risk aversion. Consumers maximize expected utility which amounts to

$$
E(u(y))=E(y)-s \operatorname{Var}(y)
$$

where $\operatorname{Var}(y)$ is the variance of the outcome variable $y$.

\subsection{No Mandated Warranty (Laissez-Faire)}

If consumers bear the risk resulting from the possibility of product failure and repair, the highcare product generates both a reduction of expected repair costs (as above) and a reduction of risk-bearing costs to zero (new). ${ }^{15}$ Our assumptions ensure that the saving in expected repair costs is in isolation not sufficient to offset the additional cost $x$, but the additional reduction in risk-bearing costs may make high care socially desirable.

Price competition ensures prices $p_{n}=c$ for the normal-care product and $p_{h}=c+x$ for the high-care product. With the normal-care product, consumer utility is $v-c$ when no product defect occurs and $v-c-r$ otherwise. In contrast, the high-care product eradicates risk and ensures the outcome $v-c-x$. We obtain:

Lemma 2 Assume a laissez-faire regime and risk-averse consumers. For low levels of risk aversion (i.e., $\left.s \leq \bar{s}=(x-\rho) /\left(\pi(1-\pi) r^{2}\right)\right)$, firms offer the normal-care product at $p_{n}=c$. For high levels of risk aversion (i.e., $s>\bar{s}$ ), firms offer the high-care product at $p_{h}=c+x$.

The equilibrium is efficient in a second-best sense. Provided consumers are risk bearers, it is socially optimal if firms offer the high-care product when consumers are sufficiently risk-averse $(s>\bar{s})$. In this case, risk-bearing costs with the normal-care product $\left(s \pi(1-\pi) r^{2}\right)$ surpass

\footnotetext{
${ }^{15}$ Note that we assume that firms take the market regulation as given. In the present setting, firms would otherwise find it optimal to offer consumers an insurance against the repair cost. Hence, the subsequent analysis is particularly relevant for situations where firms are unable to offer warranties to consumers (for example due to high transaction costs for the provision of individual clauses).
} 
the additional expected costs incurred for the high-safety variant $(x-\rho)$. If risk-aversion is less pronounced $(s \leq \bar{s})$, offering the normal-care product is second-best efficient.

\subsection{Mandated Warranty}

When a warranty is mandated, either both product variants or only the normal-care product may be traded in equilibrium. Lemma 1 still applies and an equilibrium in which only the highcare product is traded is unfeasible. The following proposition characterizes firms' equilibrium behavior.

Proposition 7 (Mandated Warranty and Competitive Firms: Risk Aversion) Assume a mandated warranty, a competitive industry, and risk-averse consumers. (i) If either both $\alpha>\bar{\alpha}=$ $\hat{\alpha}-s(1-\pi) r$ and $s \leq \bar{s}$ or $s>\bar{s}$, informed consumers buy the normal-care product at $p_{n}=c+\rho$ and uninformed consumers purchase the high-care product at $p_{h}=c+x$. (ii) If $\alpha \leq \bar{\alpha}$ and $s \leq \bar{s}$, all consumers buy the normal-care product at $p_{n}=c+\alpha \rho$.

The proposition shows that equilibrium outcomes with a mandated warranty follow a structure similar to that in the basic model. The quantitative difference pertains to the additional risk-cost incurred by uninformed consumers who purchase the normal-care product. As these consumers expect to bear repair costs themselves they perceive a variance in outcomes equal to $\pi(1-\pi) r^{2}$. Accordingly, the threshold value for the share of informed consumers above which a segmentedmarket outcome obtain is lower than that in the baseline scenario absent risk-aversion. With risk-aversion it becomes more likely that the high-care product will be offered to uninformed consumers. Figure 3 illustrates the equilibria that emerge with and without a mandated warranty for different combinations of the risk-aversion parameter and the share of informed consumers.

We can now analyze the efficiency effects of a mandated warranty. As explained above, consumers' risk aversion can make it socially desirable that the high-care product is offered. This means that the outcome in which both product variants are traded can be preferred to the outcome in which only the normal-care product is traded. However, the results in Proposition 8 clarify that the competitive equilibrium contains the high-care product in too many circumstances. 


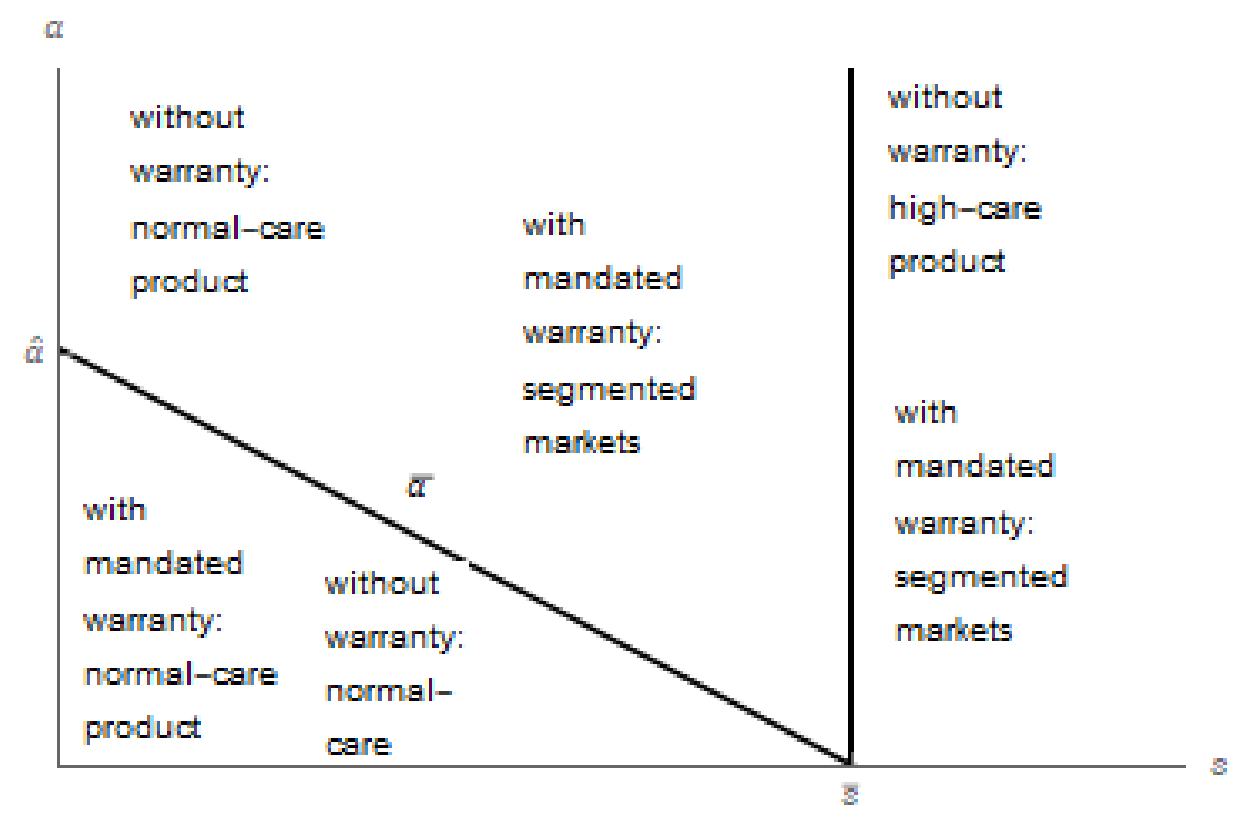

Figure 3: Type of Equilibrium, Risk Aversion, and the Share of Informed Consumers

\section{Proposition 8 (Mandated Warranty's Effects with Competitive Firms: Risk Aversion)}

Assume a mandated warranty, a competitive industry, and risk-averse consumers. (i) If $s>\bar{s}$ or both $s \leq \bar{s}$ and $x>2 \rho$, welfare is higher than in the laissez-faire regime independent of the share of informed consumers. (ii) If $s \leq \bar{s}$ and $x<2 \rho$, welfare is higher than in the laissez-faire regime when either $\alpha<\bar{\alpha}$ or $\alpha>\alpha^{*}=1-\frac{s \pi(1-\pi) r^{2}}{x-\rho}>\hat{\alpha}$. Welfare is lower due to the warranty when $\alpha \in\left[\bar{\alpha}, \alpha^{*}\right)$.

When risk aversion is large (i.e., $s>\bar{s}$ ), the mandated warranty improves the situation for informed consumers because they can obtain the cheaper normal-care product without having to bear risk costs. Uninformed consumers consume the high-care product variant with or without the warranty in place. When risk aversion is more moderate so that the high-care product is not offered in the laissez-faire regime, the mandated warranty may increase or decrease welfare. The benefits from the superior risk allocation for informed consumers may be outweighed by the additional costs if the high-care product is offered to uninformed consumers. Firms offer the highcare product for $\alpha>\bar{\alpha}$ and the adverse efficiency effect dominates for intermediate levels of the share of informed consumers as long as additional care costs are not too high $(x<2 \rho)$. With 


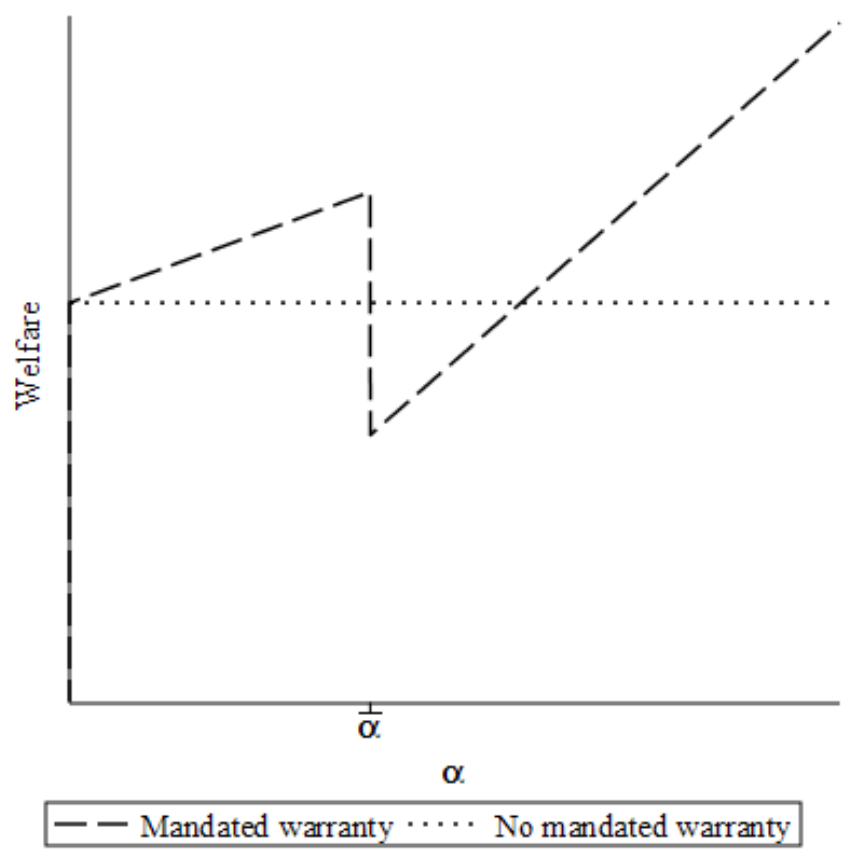

Figure 4: Welfare and the Share of Informed Consumers If $s<\bar{s}$ and $x<2 \rho$

a higher share of informed consumers the positive risk allocation effect becomes dominant. For $x>2 \rho$ the high-care product is sufficiently unattractive such that the high-care product is only introduced when the share of informed consumers is so high that a gain in overall welfare is still obtained.

Figure 4 illustrates welfare levels as a function of the share of informed consumers for $x<2 \rho$ and $s<\bar{s}$. The figure again highlights the role of consumer information. While total welfare is non-monotonic in the share of informed consumers, the highest level of welfare is achieved when consumer rights are implemented and all consumers are aware of these rights.

In terms of consumer welfare, (un)informed consumers benefit (lose) from consumer rights. However, the distributional effects might be larger compared to those from our basic model. Before, informed consumers were either indifferent or better-off due to a cross-subsidization from uninformed consumers. In the present setup, they also benefit from the eradication of risk-bearing costs. In contrast, uninformed consumers do not benefit from this risk-shifting effect, as they mistakenly believe that they still bear the risk of product failure.

Most importantly, we again find that the provision of consumer rights can be welfare reducing 
when some consumers remain ignorant of them. As was true in the two previous models, the possible welfare loss results from the offer of an excessively safe product.

\section{Conclusion}

Evidence shows that consumers have imperfect knowledge about their rights. For policy makers, it is important to understand what this implies for the desirability of market interventions. Simple intuition may suggest that the misperception of some consumers goes to their private disadvantage but is otherwise welfare-neutral.

Using a simple framework, this paper shows that the imperfect information of some consumers about their rights can cause potentially severe inefficiency. This result was established assuming

either competitive firms or a monopolist. Our finding suggests that possible misperceptions of rights are a very important factor for the determination and evaluation of economic policy interventions. Assuming risk-averse instead of risk-neutral consumers, we find that efficiency and total consumer surplus only increase from consumer rights if gains from the improved risk allocation dominate possible inefficiencies resulting from the purchase decisions by uninformed consumers.

An important implication of our analysis is to show that the welfare effects of extending consumer rights are unbalanced. While consumers who are aware of their rights can benefit, unaware consumers are even hurt. In practice, unaware consumers might be more vulnerable consumer groups which policy makers would like to protect. If policy interventions are meant exactly to protect such consumer groups our model would suggest that well-meant policies might backfire. Therefore, our paper highlights that not only the design of public policy interventions is relevant, but that consumer awareness of their rights is equally important. 


\section{References}

Armstrong, M. (2015). Search and ripoff externalities. Review of Industrial Organization, 47, 273-302.

- and Vickers, J. (2012). Consumer protection and contingent charges. Journal of Economic Literature, 50 (2), 477-493.

BAR-GiLl, O. and DAvis, K. E. (2017). (Mis)perceptions of law in consumer markets. American Law and Economics Review, 19, 245-286.

Blinder, A. S. and Krueger, A. B. (2004). What does the public know about economic policy, and how does it know it? Brookings Papers on Economic Activity, 1, 327-397.

Daughety, A. F. and Reinganum, J. F. (1995). Product safety: Liability, R\&D, and signaling. American Economic Review, 85, 1187-1206.

— and - (2006). Markets, torts, and social inefficiency. RAND Journal of Economics, 37, 300323.

Engstrom, N. (2011). Legal access and attorney advertising. American University Journal of Gender Social Policy and Law, 4, 1083-1094.

European Commission (2011). Report on Special Eurobarometer 342. Consumer Empowerment. Bruxelles.

Gabaix, X. and Laibson, D. (2006). Shrouded attributes, consumer myopia, and information suppression in competitive markets. Quarterly Journal of Economics, 121 (2), 505-540.

Garoupa, N. (1999). Optimal law enforcement with dissemination of information. European Journal of Law and Economics, 7, 183-196.

GrubB, M. D. (2015). Behavioral consumers in industrial organization: An overview. Review of Industrial Organization, 47, 247-258. 
Heidhues, P. and Köszegi, B. (2018). Behavioral industrial organization. In D. Bernheim, S. DellaVigna and D. Laibson (eds.), Handbook of Behavioral Economics, Elsevier.

KIM, P. T. (1997). Bargaining with imperfect information: A study of worker perceptions of legal protection in an at-will world. Cornell Law Review, 83, 105-160.

Polinsky, A. M. (1983). Risk sharing through breach of contract remedies. Journal of Legal Studies, 12 (2), 427-444.

Shavell, S. (1987). Economic Analysis of Accident Law. Harvard University Press.

Spence, M. (1977). Consumer misperceptions, product failure and producer liability. Review of Economic Studies, 44, 561-572.

Wobker, I., Kenning, P., Lehmann-Waffenschmidt, M. and Gigerenzer, G. (2014). What do consumers know about the economy? A test of minimal economic knowledge in Germany. Journal of Consumer Protection and Food Safety, 9, 231-242. 


\section{Appendix}

\section{Proofs of lemmas and propositions}

\section{Proof of Lemma 1}

Proof. We prove by contradiction. If informed consumers bought the high-care product, uninformed consumers would likewise do so because $q_{n}^{i} \geq q_{h}^{i}$ implies $q_{n}^{n i}=q_{n}^{i}+\rho>q_{h}^{n i}=q_{h}^{i}$. Competition ensures $p_{h}=c+x$. In this case, a firm can attract informed consumers by offering a normal-care product at price $p_{n}=c+x-\epsilon, \epsilon$ small, thereby securing a profit per unit equal to $c+x-\epsilon-(c+\rho)=x-\rho-\epsilon>0$.

\section{Proof of Proposition 1}

Proof. (i) This equilibrium requires that uninformed consumers prefer the high-care product and that firms have no incentive to deviate. Informed consumers buy the normal-care product as explained in Lemma 1. Uninformed consumers prefer the high-care product to the normalcare product as long as $q_{n}^{n i}=c+2 \rho \geq q_{h}^{n i}=c+x$, which requires $2 \rho \geq x$. For firms it can never be optimal to offer the high-care product at a price that deviates from $p_{h}$. In contrast, a firm may make a profit by undercutting the price of the normal-care product if the firm thereby attracts uninformed consumers who do not demand repair of defective products. The additional profits with uninformed consumers may suffice to cover losses incurred by also serving informed consumers. When firms serve both consumer types with the normal-care product, the expected per-unit cost amount to $c+\alpha \rho$. Uninformed consumers are willing to pay at most $\hat{p}_{n}$, where $\hat{p}_{n}+\rho=q_{h}^{n i}-\epsilon=c+x-\epsilon$, because they associate expected repair costs $\rho$ with this type of product. The deviation to $\hat{p}_{n}$ results in positive firm's profits when $\hat{p}_{n}=c+x-\rho-\epsilon \geq c+\alpha \rho$, which would require $\alpha<\hat{\alpha}=(x-\rho) / \rho$. In summary, noting that $\alpha \geq \hat{\alpha}$ implies $x<2 \rho$, the separated-markets equilibrium exists for $\alpha \geq \hat{\alpha}$.

(ii) Firms trade only the normal-care product if no firm benefits from offering the high-care 
product to uninformed consumers. Uninformed consumers would pay at most $\hat{p}_{h}=p_{n}+\rho-\epsilon=$ $c+(1+\alpha) \rho-\epsilon$ for the high-care product. This would guarantee a non-negative profit when $\hat{p}_{h}=c+(1+\alpha) \rho-\epsilon \geq c+x$. Consequently, a deviation to the high-care product is not profitable when $\alpha<\hat{\alpha}$.

\section{Proof of Proposition 3}

Proof. (i) Individual consumer welfare amounts to $v-c-\rho$ for informed consumers and $v-c-x$ for uninformed consumers. Aggregate consumer welfare amounts to $v-c-\alpha \rho+(1-\alpha) x$. Turning an uninformed consumer into an informed one increases individual and total consumer welfare as $\rho<x$. (ii) Individual consumer welfare amounts to $v-c-\alpha \rho$ for informed consumers and $v-c-(1+\alpha) \rho$ for uninformed consumers. Aggregate consumer welfare equals $v-c-\rho$. At $\alpha=\hat{\alpha}$, informed consumers' utility falls from $v-c-\hat{\alpha} \rho$ to $v-c-\rho$. Uninformed consumers' utility remains unchanged because $v-c-(1+\hat{\alpha}) \rho=v-c-x$ at $\alpha=\hat{\alpha}$. Aggregate consumer welfare decreases from $v-c-\rho$ to $v-c-\hat{\alpha} \rho-(1-\hat{\alpha}) x$.

\section{Proof of Proposition 4}

Proof. First, consider the two extreme cases where the firm sells only to informed consumers should only normal-care products be sold (i.e., when $\rho>\mathcal{R}$ ) and where the uninformed consumers' self-selection constraint is binding should the monopolistic firm offer both care levels (i.e., when $x>3 \rho)$. If $\rho>\mathcal{R}$, it is true that $\mathcal{T}>0$ and $x<3 \rho$ (since $x<1-c<(1+2 \sqrt{\alpha}) \rho<3 \rho$ ). The

firm strictly prefers to offer both products at prices $p_{n}=(1+c+\rho) / 2$ and $p_{h}=(1+c+x) / 2$ instead of offering only the normal-care product exclusively to informed consumers. If $x>3 \rho$, we have that both $\mathcal{T}<0$ and $\rho<\mathcal{R}$ (since $\rho<x / 3<(1-c) / 3<\mathcal{R}$ ) are true. The firm strictly prefers to offer only the normal-care product. This holds because, starting from a situation with both product variants, it would already be better to only sell the normal-care product without adjusting its price. For the firm, the lost revenue per uninformed consumer is equal to $\rho$ which falls short of the cost saving $x$ while uninformed consumers' demand remains unchanged. 
Next, we consider all parameter combinations in between the two extreme cases. When $\rho \leq \mathcal{R}$ and $x<3 \rho$, the firm compares profits $\Pi^{W, s e p}=\alpha \Pi^{N}+(1-\alpha)(1-c-x)^{2} / 4$ and $\Pi^{W, n o s e p}=$ $\Pi^{N}-\rho^{2} \alpha(1-\alpha)$. The firm prefers (no) separation of markets for informed and uninformed consumers if

$$
(1-\alpha) \frac{(1-c-x)^{2}}{4} \geq(<)(1-\alpha) \frac{(1-c-\rho)^{2}}{4}-\rho^{2} \alpha(1-\alpha)
$$

which results in $\mathcal{T} \geq(<) 0$.

\section{Proof of Proposition 6}

Proof. Proposition 4 describes how the market equilibrium depends on $\mathcal{T}$. With markets for high-care and low-care products, we find $\partial \Pi^{W, s e p} / \partial \alpha=\left((1-c-\rho)^{2}-(1-c-x)^{2}\right) / 4>0$ and $\partial W^{W, \text { sep }} / \partial \alpha=3 / 2 \partial \Pi^{W, \text { sep }} / \partial \alpha>0$. When only the normal-care product is offered, we obtain $\partial \Pi^{W, \text { nosep }} / \partial \alpha=-\rho^{2}(1-2 \alpha)$ and $\partial W^{W, \text { nosep }} / \partial \alpha=-\rho^{2}(1-2 \alpha) / 2$.

\section{Proof of Lemma 2}

Proof. The expected outcome and variance from consuming the normal-care product are $v-c-\rho$ and $\pi(1-\pi) r^{2}$. With the high-care product consumers achieve expected utility $v-c-x$. In equilibrium, firms offer the product that maximizes consumers' expected utility resulting in the critical value for risk-aversion $\bar{s}$.

\section{Proof of Proposition 7}

Proof. Informed consumers always purchase the normal-care product in equilibrium. When both product variants are offered, uninformed consumers achieve expected utility $v-c-x$. In order to induce uninformed consumers to purchase the normal-care product instead, a firm would have to set the product's price $\bar{p}_{n}$ such that $v-\bar{p}_{n}-\rho-s \pi(1-\pi) r^{2} \geq v-c-x$ resulting in $\bar{p}_{n} \leq c+x-\rho-s \pi(1-\pi) r^{2}$. Non-negative profits result only for $\bar{p}_{n} \geq c+\alpha \rho$ that is if $\alpha<\bar{\alpha}$. Reversing the argument, with only the normal-care product on offer, each firm charges 
$p_{n}=c+\alpha \rho$ and only if $\alpha>\bar{\alpha}$ applies will uninformed consumers be better off from buying the high-care product at a price that allows for non-negative profits.

\section{Proof of Proposition 8}

Proof. For $s>\bar{s}$, uninformed consumers are equally well-off in both regimes, consuming a highsafety product at price $c+x$. However, informed consumers are better off with the mandated warranty as it delivers both no risk-bearing costs and the cheaper normal-care product.

With a mandated warranty and $s \leq \bar{s}$, welfare amounts to $\alpha(v-c-\alpha \rho)+(1-\alpha)(v-c-(1+$ $\left.\delta) \rho-s \pi(1-\pi) r^{2}\right)=v-c-\rho-(1-\alpha) s \pi(1-\pi) r^{2}$ for $\alpha<\bar{\alpha}$ and $\alpha(v-c-\rho)+(1-\alpha)(v-c-x)=$ $v-c-\rho-(1-\alpha)(x-\rho)$ for $\alpha>\bar{\alpha}$. Welfare is increasing in $\alpha$ for $\alpha \in(0, \bar{\alpha})$ and for $\alpha \in(\bar{\alpha}, 1)$. At $\alpha=0$, welfare with or without a mandated warranty coincide. At $\alpha=\bar{\alpha}$, where the trading of both product variants starts, welfare exhibits a downward jump and amounts to $v-c-\rho-(1-\bar{\alpha})(x-\rho)$, whereas welfare without the warranty amounts to $v-c-\rho-s \pi(1-\pi) r^{2}=v-c-x+\bar{\alpha} \rho$. At $\alpha=\bar{\alpha}$ welfare with a mandated warranty is lower than welfare with no warranty if $x<2 \rho$.

With $s<\bar{s}$ and $x<2 \rho$, there exists a value $\alpha^{*} \in(\bar{\alpha}, 1)$ for which welfare with and without a mandated warranty coincide. The level $\alpha^{*}$ follows from $v-c-\rho-s \pi(1-\pi) r^{2}=v-c-\rho-(1-$ $\left.\alpha^{*}\right)(x-\rho)$.

\section{Monopolistic profit maximization with a mandated war-}

\section{ranty}

\section{Markets for Normal- and High-Care Products}

The partial derivatives with respect to prices $p_{n}$ and $p_{h}$ are given by

$$
\frac{\partial \Pi}{\partial p_{n}}=\alpha\left(1-2 p_{n}+c+\rho\right)
$$


and

$$
\frac{\partial \Pi}{\partial p_{h}}=(1-\alpha)\left(1-2 p_{h}+c+x\right)
$$

The unrestricted profit-maximizing prices

$$
p_{n}=\frac{1+c+\rho}{2} \quad p_{h}=\frac{1+c+x}{2}
$$

imply $p_{h}>p_{n}$ due to $x>\rho$ such that the self-selection constraint for informed consumers is never binding. The self-selection constraint for uninformed consumers is binding if $(x-\rho) / 2>\rho$ or $x>3 \rho$. In this case, the prices $p_{n}$ and $p_{h}$ that maximize profits results from

$$
\alpha\left(1-2 p_{n}+c+\rho\right)+(1-\alpha)\left(1-2 p_{n}-2 \rho+c+x\right)=0
$$

and $p_{h}=p_{n}+\rho$.

\section{Market Only for Normal-Care Products}

The partial derivative of profits with respect to the price $p_{n}$ is

$$
\frac{\partial \Pi}{\partial p_{n}}= \begin{cases}1-2 p_{n}+c+\rho-2(1-\alpha) \rho & \text { for } p_{n}<1-\rho \\ \alpha\left(1-2 p_{n}+c+\rho\right) & \text { for } p_{n}>1-\rho\end{cases}
$$

The derivative exhibits an upward jump from $(2 \alpha+1) \rho-1+c$ to $3 \rho-1+c$ at $p_{n} \rightarrow 1-\rho$. Consequently, if $\rho<(1-c) / 3$ the profit maximum is obtained for $p_{n}<1-\rho$ for sure and if $\rho>(1-c) /(2 \alpha+1)$ the profit maximum necessarily requires $p_{n}>1-\rho$. For $(1-c) / 3<\rho<$ $(1-c) /(2 \alpha+1)$ we need to compare profits for $p_{n}=(1+c+\rho) / 2-(1-\alpha) \rho=p_{n 1}$ for which both consumer groups are served and for $p_{n}=(1+c+\rho) / 2=p_{n 2}$ with only informed consumers buying the product. We have

$$
\Pi\left(p_{n 1}\right)=\frac{(1-c-\rho)^{2}}{4}-\rho^{2} \alpha(1-\alpha) \text { and } \Pi\left(p_{n 2}\right)=\frac{\alpha(1-c-\rho)^{2}}{4}
$$


where

$$
\Pi\left(p_{n 1}\right) \geq \Pi\left(p_{n 2}\right) \Leftrightarrow \rho \leq \mathcal{R}=\frac{1-c}{1+2 \sqrt{\alpha}} .
$$


Download ZEW Discussion Papers from our ftp server:

https://www.zew.de/en/publications/zew-discussion-papers

or see:

https://www.ssrn.com/link/ZEW-Ctr-Euro-Econ-Research.html

https://ideas.repec.org/s/zbw/zewdip.html

//

ZEW - Leibniz-Zentrum für Europäische Wirtschaftsforschung GmbH Mannheim

ZEW - Leibniz Centre for European

Economic Research

L 7,1 68161 Mannheim · Germany

Phone +49621 1235-01

info@zew.de·zew.de

Discussion Papers are intended to make results of ZEW research promptly available to other economists in order to encourage discussion and suggestions for revisions. The authors are solely responsible for the contents which do not necessarily represent the opinion of the ZEW. 